\title{
Intracellular distribution of amyloid beta peptide and its relationship to the lysosomal system
}

\author{
Lin Zheng ${ }^{1 *}$, Angel Cedazo-Minguez ${ }^{2}$, Martin Hallbeck ${ }^{3,4}$, Fredrik Jerhammar ${ }^{5}$, Jan Marcusson ${ }^{1}$ and Alexei Terman ${ }^{6}$
}

\begin{abstract}
Background: Amyloid beta peptide $(A \beta)$ is the main component of extraneuronal senile plaques typical of Alzheimer's disease (AD) brains. Although $A \beta$ is produced by normal neurons, it is shown to accumulate in large amounts within neuronal lysosomes in $A D$. We have recently shown that under normal conditions the majority of $A \beta$ is localized extralysosomally, while oxidative stress significantly increases intralysosomal $A \beta$ content through activation of macroautophagy. It is also suggested that impaired $A \beta$ secretion and resulting intraneuronal increase of $A \beta$ can contribute to $A D$ pathology. However, it is not clear how $A \beta$ is distributed inside normal neurons, and how this distribution is effected when $A \beta$ secretion is inhibited.

Methods: Using retinoic acid differentiated neuroblastoma cells and neonatal rat cortical neurons, we studied intracellular distribution of $A \beta$ by double immunofluorescence microscopy for $A \beta_{40}$ or $A \beta_{42}$ and different organelle markers. In addition, we analysed the effect of tetanus toxin-induced exocytosis inhibition on the intracellular distribution of $A \beta$.

Results: Under normal conditions, A $\beta$ was found in the small cytoplasmic granules in both neurites and perikarya. Only minor portion of $A \beta$ was colocalized with trans-Golgi network, Golgi-derived vesicles, early and late endosomes, lysosomes, and synaptic vesicles, while the majority of A $\beta$ granules were not colocalized with any of these structures. Furthermore, treatment of cells with tetanus toxin significantly increased the amount of intracellular $A \beta$ in both perikarya and neurites. Finally, we found that tetanus toxin increased the levels of intralysosomal $A \beta$ although the majority of $A \beta$ still remained extralysosomally.
\end{abstract}

Conclusion: Our results indicate that most $A \beta$ is not localized to Golgi-related structures, endosomes, lysosomes secretory vesicles or other organelles, while the suppression of A $\beta$ secretion increases intracellular intra- and extralysosomal $A \beta$.

Keywords: Alzheimer disease, Amyloid $\beta$-protein, Colocalization, Exocytosis, Immunocytochemistry, Lysosomes

\section{Introduction}

The mechanisms behind Alzheimer disease (AD), the main cause of senile dementia, are poorly understood. One of the important hallmarks of $\mathrm{AD}$ is the formation of extracellular senile plaques, preferentially composed of amyloid beta-protein [1]. The most common isoforms of $A \beta$ are $A \beta_{40}(90 \%)$ and $A \beta_{42}(10 \%)$, the latter being more toxic, more prone to aggregation, more resistant to degradation, and specifically increases in all forms of familial AD [2].

\footnotetext{
* Correspondence: lin.zheng@liu.se

'Division of Geriatric Medicine, Department of Clinical and Experimental Medicine, IKE, Faculty of Health Sciences, Linköping University, Linköping SE-581 85, Sweden

Full list of author information is available at the end of the article
}

$A \beta$ is proteolytically cleaved from a large transmembrane amyloid precursor protein (APP) by $\beta$ and $\gamma$ secretases [3]. APP is normally synthesized in the endoplasmic reticulum (ER) and transported to the Golgi apparatus. Eventually it can be trafficked from the trans-Golgi network (TGN) to the cell surface and secreted into extracellular space [4], recycled back to the Golgi complex for further packaging and trafficking [5] or reinternalized from the cell surface into the endosomal-lysosomal system via endocytosis [6-8]. A $\beta$ generation from APP is thought to occur in a variety of organelles where APP, $\beta$ and $\gamma$ secretase reside. Thus, $A \beta$ has been found in many intracellular sites, such as ER, Golgi complexes, mitochondria, endosomes, lysosomes, multivesicular bodies (MVB), and

\section{Biomed Central}

(c) 2012 Zheng et al.; licensee BioMed Central Ltd. This is an Open Access article distributed under the terms of the Creative Commons Attribution License (http://creativecommons.org/licenses/by/2.0), which permits unrestricted use, distribution, and reproduction in any medium, provided the original work is properly cited. 
cytosol (reviewed in [9]). Autophagic vacuoles have also been shown involved in the production of $A \beta[10]$.

The toxicity of $A \beta$ and its involvement in senile plaque formation are considered important pathophysiological targets for primary prevention in $\mathrm{AD}$ (reviewed in [11]). It has been proposed that senile plaques originate from intraneuronal $A \beta$ as a result of its release after neuronal death [12]. Intracellular $A \beta$ has been pointed out to be involved in early stages of the disease, directly causing neurotoxicity and initiating AD pathology [12-19]. It has been reported recently that $A \beta$-related synapse damage and memory impairment in AD-transgenic mice correlated with intracellular levels of $A \beta$ but not with plaque burden [20]. Moreover, cultured neurons from ADtransgenic mice showed reduced secretion and enhanced intracellular accumulation of $A \beta$ [21]. Much evidence supports that the lysosomal system, a vacuolar compartment with acidic $\mathrm{pH}(3.5-6.0)$, is associated with $\mathrm{A} \beta$ generation and neurotoxicity [22-26]. In $\mathrm{AD}$ and experimental AD models, $A \beta$ has been detected in abnormally enlarged endosomes [12,17,27], autophagosomes [10], and lysosomes [28-30].

Our previous studies showed that normobaric hyperoxia (a chronic, mild oxidative stress) enhanced macroautophagy, inducing intralysosomal $\mathrm{A} \beta$ accumulation, lysosomal membrane permeabilization and consequent apoptosis [29-32]. However, it is not clear how $A \beta$ is distributed in relation to the lysosomal system and other organelles normally and how and why this distribution is changed in $\mathrm{AD}$. Here we studied the relation of $\mathrm{A} \beta$ to the lysosomal vacuolar compartment (early and late endosomes, lysosomes and autolysosomes) as well as to cellular structures associated with related process of protein secretion (such as Golgi-derived secretory vesicles and synaptic vesicles) using double immunofluorescence microscopy (for $A \beta$ and different organelle markers). RA-differentiated neuroblastoma cells and neonatal rat cortical neurons were used as in vitro models. Cells were cultured under normal conditions as well as in the presence of the exocytosis inhibitor, tetanus toxin (TeNT).

\section{Materials and methods}

\section{Human neuroblastoma SH-SY5Y cell culture}

Human SH-SY5Y neuroblastomacells were obtained from the American Type Culture Collection (Rockville, MD, USA) and cultured in Dulbecco's Modified Eagle Medium (DMEM; Gibco, Paisley, UK) supplemented with $4500 \mathrm{mg} / \mathrm{l}$ glucose, $110 \mathrm{mg} / \mathrm{l}$ sodium pyruvate, $584 \mathrm{mg} / \mathrm{l}$ glutamine, $10 \%$ fetal bovine serum, $50 \mathrm{IU} / \mathrm{ml}$ penicillin $\mathrm{G}$ and $50 \mathrm{mg} / \mathrm{ml}$ streptomycin in $25 \mathrm{~cm}^{2}$ plastic culture flasks (Corning, Corning, NY, USA) at $37^{\circ} \mathrm{C}$, with $5 \% \mathrm{CO}_{2}$. For differentiation, neuroblastoma cells were exposed to $10 \mu \mathrm{M}$ all-trans retinoic acid (RA,
Sigma, St. Louis, MO, USA) for 14 days. The medium was changed every second day.

\section{Neonatal rat cortical neuron culture}

Primary culture of neonatal rat cortical neurons was prepared as described previously [33]. Neurons were obtained from the cerebral cortex of newborn Wistar rats and plated onto $35 \mathrm{~mm}$ Petri dishes coated with poly-D-lysine (Sigma). The culture medium consisted of DMEM (Gibco) containing 20\% fetal bovine serum, $2.5 \mu \mathrm{g} / \mathrm{ml}$ insulin and $45 \mathrm{mM}$ glucose. The percentage of fetal bovine serum was gradually reduced to $5 \%$. The medium was changed twice a week.

\section{Inhibition of exocytosis}

Tetanus toxin (TeNT, Sigma), an exocytosis inhibitor, was used to block the transport of secretory vesicles to the plasma membrane [34]. RA differentiated neuroblastoma cells and primary neurons were treated with 5 or $20 \mathrm{nM}$ tetanus toxin (TeNT) respectively for $24 \mathrm{~h}$.

\section{Antibodies}

Primary anti- $\mathrm{A} \beta_{1-42}$ antibodies [35] (Chemicon, Temecula, CA, USA), and anti-A $\beta_{1-40}$ antibodies [36,37] (Chemicon, Temecula, CA, USA), were rabbit polyclonal, while antihuman-Rab8 [38] (marker for TGN and Golgi-derived secretory vesicles, BD biosciences, Franklin Lakes, NJ, USA), anti-Rab9 [39] (marker for TGN and late endosomes, Abcam, Cambridge, UK), anti-Rab5 (marker for early endosomes, Pharmingen, San Diego, CA, USA), antiLAMP-2 (marker for lysosomes and late endosomes, Southern Biotechnology, Birmingham, AL, USA), antiVAMP 2 (synaptobrevin/VAMP 2, marker for synaptic vesicles, Synaptic Systems, Göttingen, Germany), and antiRab3 (marker for synaptic vesicles, Synaptic Systems) antibodies were mouse monoclonal IgG. Secondary antibodies were Alexa Fluor 488-conjugated goat anti-rabbit IgG and Alexa Fluor 546-conjugated goat anti-mouse IgG (both from Molecular Probes, Eugene, OR, USA).

The anti-A $\beta_{42}$ antibodies (Chemicon) are specific for C-termini of $A \beta$ peptide, and they do not cross-react with full-length APP, APP C-terminal fragments (CTF), or with $A \beta_{40}$ [40]. We have also tested the specificity of anti-A $\beta_{40}$ and anti-A $\beta_{42}$ antibodies doing double immunostaining for $\mathrm{A} \beta$ and APP in control neuroblastoma cells. The anti-APP antibodies (Zymed, mouse anti-APP, clone LN27) recognize epitope within the first 200 amino acids in the APP $\mathrm{N}$-terminus and react with all three known APP proteins. There is no cross-reactivity between $A \beta$ and APP.

\section{Immunofluorescence microscopy}

For immunofluorescence microscopy, cells on coverslips were washed twice in phosphate-buffered saline (PBS) 
and fixed in $4 \%$ neutral phosphate-buffered formaldehyde for $20 \mathrm{~min}$ at room temperature, rinsed in PBS, permeabilized with $0.1 \%$ saponin in PBS containing 5\% serum for $20 \mathrm{~min}$ and incubated with primary antibodies for either single or double immunofluorescence for $1 \mathrm{~h}$, followed by rinsing in PBS and $1 \mathrm{~h}$ incubation with secondary antibodies. Dilutions were 1:100 and 1: 400 for primary and secondary antibodies, respectively. For double immunostaining, different primary or secondary antibodies were applied simultaneously. The experiments were repeated at least three times.

After washing in PBS and distilled water, the specimens were mounted in Vectashield containing DAPI (Vector Laboratories, H-1200) and inspected with an inverted confocal laser scanning microscope (LSM 510 META, Zeiss) using a $488 \mathrm{~nm}$ argon laser and $543 \mathrm{~nm}$ helium-neon laser. For colocalization assessment, optical sections were no thicker than $0.6 \mu \mathrm{M}$. We also performed Nikon Microphot-SA fluorescence microscopy using a standard FITC / Texas Red double band-pass filter. Images were taken with a Hamamatsu ORCA 100 color digital camera (Hamamatsu, Japan). Images were prepared with Adobe Photoshop 7.0 (Adobe System).

\section{Results}

Exposure of neuroblastoma SH-SY5Y cells to RA for two weeks resulted in their differentiation, which was characterized by the suppression of mitotic activity and development neurites (Figure 1A and C). Neonatal cortical neurons showed multiple anastomosing neurites. (Figure $1 \mathrm{~B}$ and $\mathrm{D}$ ). $\mathrm{A} \beta_{42}$ immunostaining showed intracellular localization of $A \beta_{42}$ in both cell types. $A \beta$

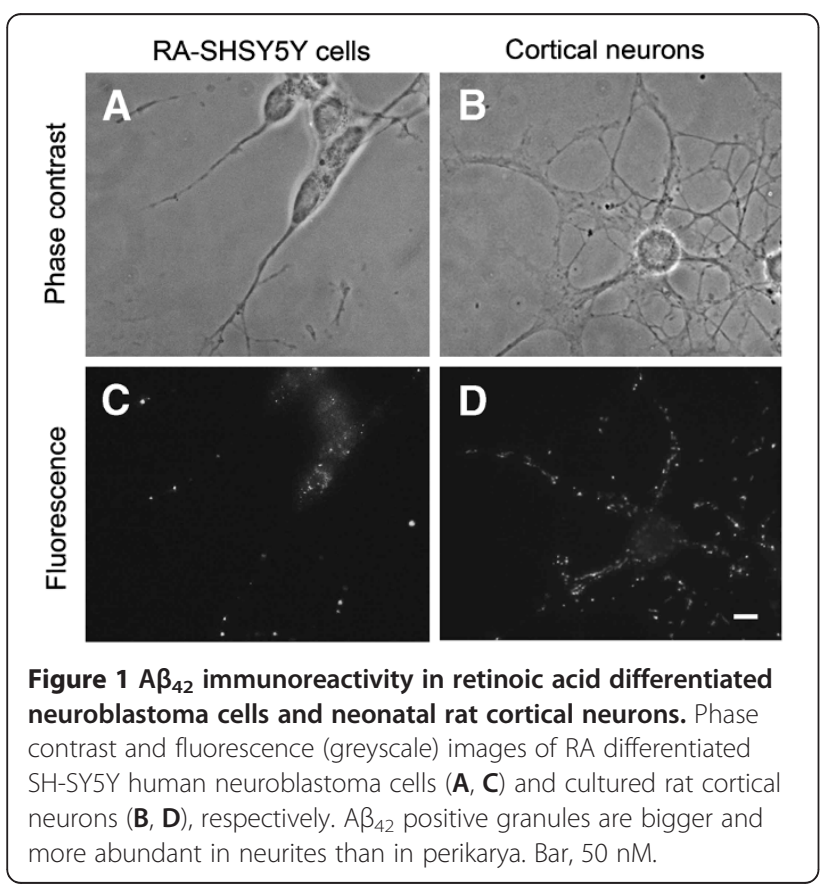

granules were larger and more abundant in neurites than in perikarya (Figure 1).

To investigate intracellular localization of $A \beta$ and its relationship with the lysosomal system and other organelles, RA differentiated neuroblastoma cells cultured under normal conditions were double immunostained for monomeric $A \beta\left(A \beta_{40}\right.$ and $\left.A \beta_{42}\right)$ and different organelle-specific proteins. As shown in Figure 2, very few $A \beta_{42}$ positive granules is colocalized with rab8 (TGN and Golgi derived vesicles marker), rab9 (TGN and late endosome marker), LAMP-2 (late endosome and lysosome marker), rab5 (early endosome marker), rab3 (exocytotic vesicle marker) or VAMP2 (or synaptobrevin, marker for synaptic vesicles). The overwhelming majority of $A \beta_{42}$ granules were not colocalized with any of the markers. As shown in Figure 3, the intracellular distribution of $A \beta_{40}$ is more diffused than that of $A \beta_{42}$. Double immunostaining of $A \beta_{40}$ and different organelle markers showed similar results regarding colocalization with organelles (Figure 3 ).

To study $A \beta$ localization in relation with different subcellular compartments, we performed immunogold electron microscopy using antibodies for $A \beta_{40}$ and $A \beta_{42}$. Low amount of $A \beta$ labeling was found in the endoplasmic reticulum, Golgi complexes, lysosomal compartment and also mitochondria, but it was particularly abundant in the cytosol, usually in the form of clusters (Zheng et al., unpublished results).

To study whether $A \beta$ relation to lysosomes depends on its secretion, RA differentiated neuroblastoma cells were exposed to the exocytosis inhibitor TeNT, followed by double immunostaining for $A \beta_{42}$ and LAMP-2. Cells were cultured under normal conditions (control) or treated with $5 \mathrm{nM}$ TeNT for $24 \mathrm{~h}$. The staining for both $\mathrm{A} \beta_{42}$ and LAMP- 2 was brighter after the treatment with TeNT, suggesting the increase in the amount of intracellular $A \beta_{42}$ as well as in the size of the lysosomal compartment. Both the size and the number of $\mathrm{A} \beta_{42}$-positive granules was increased after TeNT administration. Furthermore, although most $A \beta_{42}$ granules were still found extralysosomally, more of them than in untreated cells were colocalized with LAMP-2 positive structures (Figure 4).

The effect of exocytosis inhibition on the intracellular distribution of $A \beta_{42}$ was also studied using neonatal cortical neurons, which were exposed to $20 \mathrm{nM}$ TeNT for $24 \mathrm{~h}$. Phase contrast images show increased neuronal damage after TeNT treatment as compared to controls, while immunofluorescence microscopy reveals larger and more abundant $A \beta_{42}$ positive granules along the neuritis, reflecting disturbed $A \beta$ secretion and intraneuronal $A \beta$ accumulation (Figure 5).

\section{Discussion}

A large number of studies have explored the intracellular sites of $A \beta$ production, mostly in $A D$ models. $A \beta_{42}$ and 

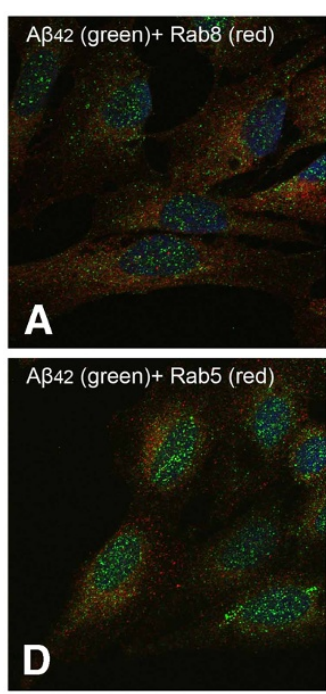
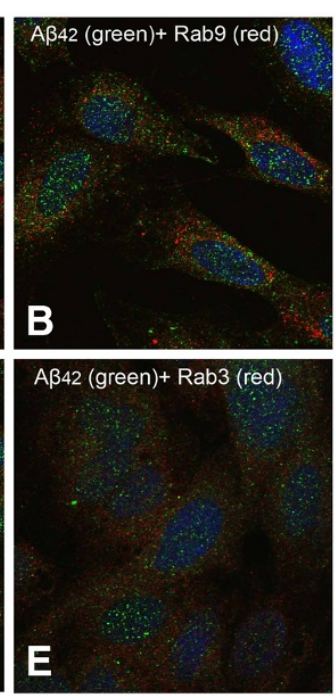

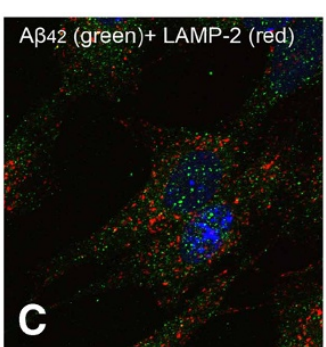

A 42 (green)+ VAMP2 (red)

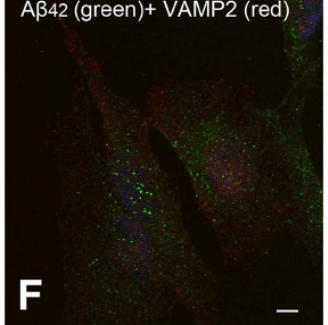

Figure 2 Double immunostaining for $A \beta_{42}$ (green fluorescence) and different subcellular markers (red fluorescence) in RA differenatiated SH-SY5Y cells. (A) Rab8 (Golgi derived vesicles marker), (B) Rab9 (trans-Golgi network, Golgi-derived vesicles and late endosome marker), (C) LAMP-2 (late endosome and lysosome marker), (D) Rab5 (early endosome marker), (E) Rab3 (exocytotic vesicle marker) and (F) VAMP2 (synaptobrevin, marker for synaptic vesicles) were used as subcellular organelle markers. Scale bar, 5 Hm.

$\mathrm{A} \beta_{40}$ monomers have been previously demonstrated in ER [6-8], TGN [41] and post-TGN secretory vesicles [8], mitochondria [42], endosomes [27], lysosomes [43], multivesicular bodies (MVB) [44], and cytosol [12,45-47]. However, little is known about intracellular localization of $A \beta$ in normal conditions, when $A \beta$ is not overproduced.

In this study, we demonstrated that in differentiated neuroblastoma cells cultured under normal in vitro conditions, only little $A \beta$ (including $A \beta_{42}$ and $A \beta_{40}$ ) showed colocalization with organelles such as TGN, Golgi-derived vesicles, early and late endosomes, lysosomes, or exocytotic vesicles, while the greater part of $A \beta$ was located in the cytosol or in undetermined compartments.

The absence of major $A \beta$ immunoreactivity in these cellular compartments, in which it was found in $\mathrm{AD}$, as well as in cellular and in vivo AD models, suggests that, under normal conditions, this peptide is either relocated, or degraded, or secreted extracellularly. The fact that lysosomes showed little $A \beta$ immunoreactivity would suggest that cells are able to perform a rapid proteolytic digestion of this peptide under normal biological conditions. In support of this hypothesis, we have previously shown that
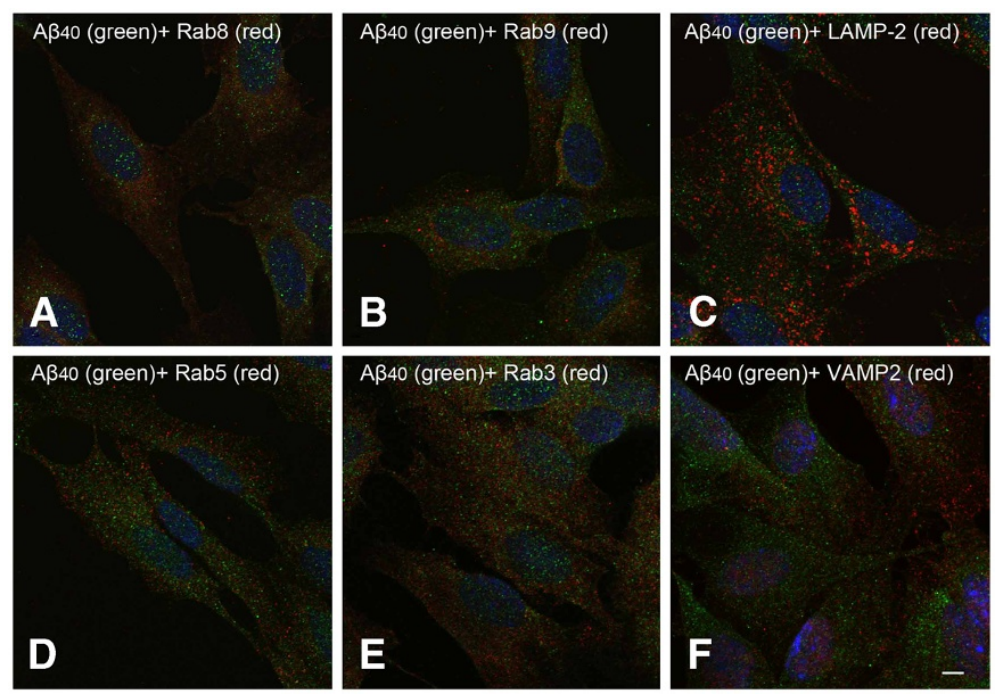

Figure 3 Double immunostaining for $A \beta_{40}$ (green fluorescence) and different subcellular markers (red fluorescence) in RA differenatiated SH-SY5Y cells. (A-F), see Figure 2. Scale bar, $5 \mu \mathrm{m}$. 


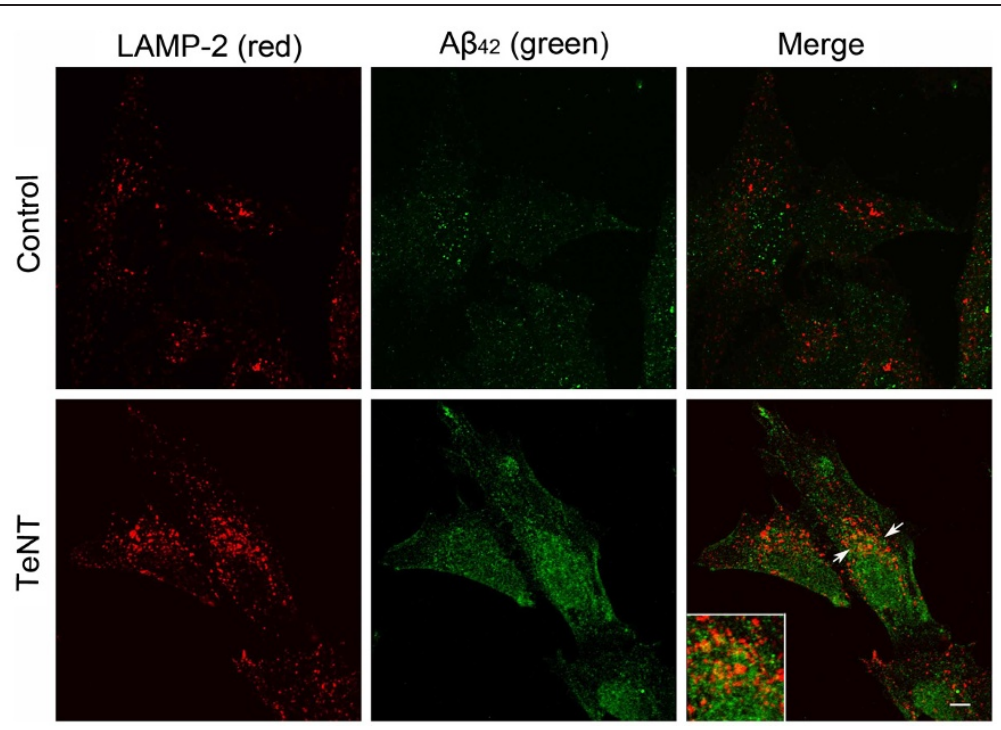

Figure 4 Double immunostaining for $A \beta_{42}$ (green fluorescence) and lysosomal/late endosomal marker LAMP2 (red fluorescence) in RA differenatiated SH-SY5Y cells cultured under normal conditions or exposed to exocytosis inhibitor tetanus toxin (TeNT, $5 \mathrm{nM}$ ) for $24 \mathrm{~h}$. Both $A \beta_{42}$ and LAMP-2 specific fluorescence are increased in tetanus toxin exposed cells, and the colocalization of A $\beta_{42}$ with LAMP-2 positive structures (arrow and corresponding inset) is increased after TeNT treatment. Scale bar, $5 \mu \mathrm{m}$.

inhibition of lysosomal enzymes induces $A \beta$ accumulation within the lysosomal compartment [29].

In addition, we have found that inhibition of exocytosis by TeNT induced a general increase of intracellular $A \beta$, both intra- and extralysosomal. As we previously reported [30], the intralysosomal $A \beta$ accumulation can be mediated by enhanced $A \beta$ autophagy. It is also possible that inhibition of exocytosis results in $A \beta$ accumulation along the
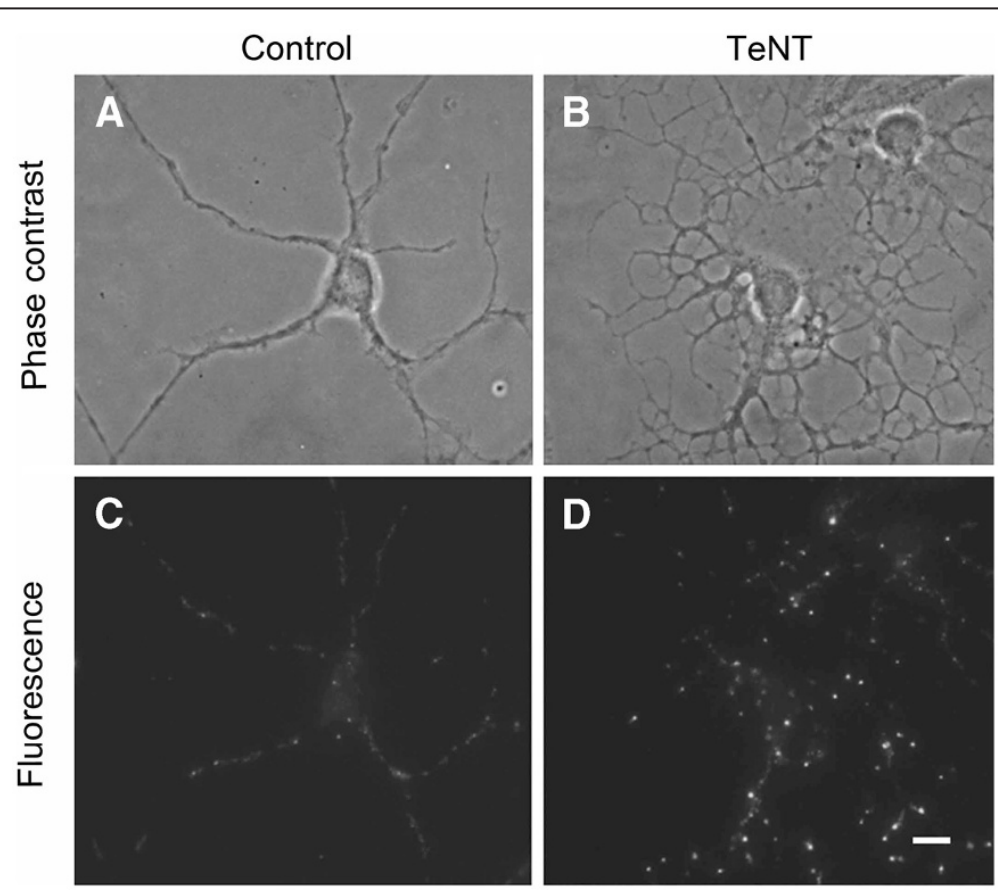

Figure $5 \mathrm{~A} \beta_{42}$ immunoreactivity (greyscale) of neonatal rat cortical neurons (A, C) cultured (under normal conditions (control) or (B, D) exposed to $20 \mathrm{nM}$ exocytosis inhibitor tetanus toxin (TeNT) for $\mathbf{2 4} \mathbf{~ h}$. (A and B) phase contrast images, (B and D) fluorescence images of corresponding cells. Both drugs induce intracellular accumulation of $A \beta_{42}$. Bar, $50 \mathrm{nM}$. Intraneuronal $A \beta_{42}$ is increased and accumulated in the neurites. 
secretory pathway, including ER, Golgi apparatus, transport visicles and secretory vesicles [48].

Although under normal conditions late endosomes and lysosomes seem to be free of $A \beta$, this is not the case for $\mathrm{AD}$ neurons, in which $\mathrm{A} \beta$ has been demonstrated intralysosomally $[10,27,28]$. It is not clear what causes these changes and how $A \beta$ relocation to lysosomes contributes to the pathogenesis of $\mathrm{AD}$. One possible explanation is that oxidative stress might enhance autophagy, leading to intralysosomal $A \beta$ accumulation, consequent lysosomal membrane damage and release of lysosomal enzymes to the cytosol, culminating in apoptosis $[29,30]$.

In $\mathrm{AD}, \mathrm{A} \beta$ has been shown to accumulate within lysosomes, apparently promoting neuronal death through lysosomal destabilization [22,25,49]. As we previously demonstrated, intralysosomal $\mathrm{A} \beta$ accumulation can be triggered by oxidative stress and consequent activation of macroautophagy $[29,30]$. On the other hand, $A \beta$ has been shown to induce oxidant-mediated autophagic cell death in cultured cells [50], while antioxidants can protect cells from $\mathrm{A} \beta$-mediated oxidative damage [51].

The fact that in the majority of AD cases there is no consistent overproduction of $A \beta$ suggests that deficits in its degradation could lie behind the pathogenesis of the disease. On the other hand, intracellular accumulation of $A \beta$ is proposed to compromise normal neuronal function in $\mathrm{AD}$. Our findings demonstrate that, under normal conditions, intracellular $A \beta$ (including $A \beta_{42}$ and $A \beta_{40}$ ) is mainly associated with cytosolic structures and, to a large extent, is secreted from the cells. They may also suggest that deficits in secretion or lysosomal processing would result in intracellular $A \beta$ accumulation and its translocation to the cellular organelles, as seen in $\mathrm{AD}$ and its models $[12,21,52,53]$. Our finding may contribute to better understanding of $\mathrm{AD}$ pathogenesis, and may help develop new therapeutic strategies against $\mathrm{AD}$ (reviewed in [54]).

\section{Abbreviations}

AD: Alzheimer disease; AB: Amyloid $\beta$-protein; APP: Amyloid Precursor Protein; ER: Endoplasmic Reticulum; PBS: Phosphate-buffered Saline; LAMP2: Lysosomal Associated Membrane Protein-2; MPRs: Mannose 6-phosphate Receptors; RA: Retinoic Acid; TeNT: Tetanus Toxin; TGN: Trans Golgi network.

\section{Competing interests}

The author(s) declare that they have no competing interests.

\section{Authors' contributions}

LZ carried out experiments, participated in manuscript writing and revision, AC-M participated in project design and manuscript writing, $\mathrm{MH}$ participated in project design, FJ participated in part of experiments, JM participated in project design, AT participated in project design, manuscript writing and revision. All authors read and approved the final manuscript.

\section{Acknowledgments}

This work was supported by the Gustav V and Queen Victoria Foundation (JM) County Council of Östergötland (JM, LZ, MH), Stiftelsen Olle Engkvist Byggmästare (LZ), Stiftelsen för Gamla Tjänarinnor (LZ, AC-M), Loo and Hans Ostermans foundation (LZ), Gun och Bertil Stohnes Stiftelse (LZ, AC-M), Lions
Forskningsfond (LZ), Svenska Lundbeckstiftelsen (LZ), Karolinska Institute Fund for Geriatric Research (AC-M), Alice och Knut Wallenberg Stiftelse (AC-M), Swedish Alzheimer Foundation (MH) and The Swedish Brain Power (AC-M).

\section{Author details}

'Division of Geriatric Medicine, Department of Clinical and Experimental Medicine, IKE, Faculty of Health Sciences, Linköping University, Linköping SE-581 85, Sweden. ${ }^{2}$ KI-AlzheimerDisease Research Center, NVS, Novum, Karolinska Institutet, Stockholm SE-141 57, Sweden. ${ }^{3}$ Division of Pathology, Department of Clinical and Experimental Medicine, IKE, Faculty of Health Science, Linköping University, Linköping SE-581 85, Sweden. ${ }^{4}$ Departmentof Pathology, Linköping University Hospital, Linköping SE-581 85, Sweden. ${ }^{5}$ Experimental Pathology, Department of Clinical and Experimental Medicine, IKE, Faculty of Health Science, Linköping University, Linkoping SE-581 85, Sweden. ${ }^{6}$ Department of Clinical Pathology and Cytology, Karolinska University Hospital, Stockholm SE-141 86Huddinge, Sweden.

Received: 5 January 2012 Accepted: 13 September 2012

Published: 26 September 2012

\section{References}

1. Masters $\mathrm{CL}$, Beyreuther $\mathrm{K}$ : Pathways to the discovery of the Abeta amyloid of Alzheimer's disease. J Alzheimers Dis 2006, 9(3 Suppl):155-161.

2. Selkoe DJ: The genetics and molecular pathology of Alzheimer's disease: roles of amyloid and the presenilins. Neurol Clin 2000, 18(4):903-922.

3. Selkoe DJ: Alzheimer's disease: genes, proteins, and therapy. Physiol Rev 2001, 81(2):741-766.

4. Sisodia SS: Beta-amyloid precursor protein cleavage by a membranebound protease. Proc Natl Acad Sci USA 1992, 89(13):6075-6079.

5. Rogaeva E, et al: The neuronal sortilin-related receptor SORL1 is genetically associated with Alzheimer disease. Nat Genet 2007, 39(2):168-177.

6. Cook DG, et al: Alzheimer's A beta(1-42) is generated in the endoplasmic reticulum/intermediate compartment of NT2N cells. Nat Med 1997, 3(9):1021-1023.

7. Hartmann T, et al: Distinct sites of intracellular production for Alzheimer's disease A beta40/42 amyloid peptides. Nat Med 1997, 3(9):1016-1020.

8. Greenfield JP, et al: Endoplasmic reticulum and trans-Golgi network generate distinct populations of Alzheimer beta-amyloid peptides. Proc Natl Acad Sci USA 1999, 96(2):742-747.

9. LaFerla FM, Green KN, Oddo S: Intracellular amyloid-beta in Alzheimer's disease. Nat Rev Neurosci 2007, 8(7):499-509.

10. Yu WH, et al: Macroautophagy-a novel Beta-amyloid peptide-generating pathway activated in Alzheimer's disease. J Cell Biol 2005, 171(1):87-98.

11. Serge G, et al: Prevention strategies for Alzheimeris disease. Translational Neurodegeneration 2012, 1(13). doi:10.1186/2047-9158-1-13.

12. Gouras GK, et al: Intraneuronal Abeta42 accumulation in human brain Am J Pathol 2000, 156(1):15-20

13. Naslund J, et al: Correlation between elevated levels of amyloid betapeptide in the brain and cognitive decline. JAMA 2000, 283(12):1571-1577.

14. Gouras GK, et al: Intraneuronal beta-amyloid accumulation and synapse pathology in Alzheimer's disease. Acta Neuropathol 2010, 119(5):523-541.

15. D'Andrea MR, et al: Evidence that neurones accumulating amyloid can undergo lysis to form amyloid plaques in Alzheimer's disease. Histopathology 2001, 38(2):120-134

16. Wirths $\mathrm{O}$, et al: Intraneuronal Abeta accumulation precedes plaque formation in beta-amyloid precursor protein and presenilin-1 doubletransgenic mice. Neurosci Lett 2001, 306(1-2):116-120.

17. Takahashi RH, et al: Intraneuronal Alzheimer abeta 42 accumulates in multivesicular bodies and is associated with synaptic pathology. Am J Pathol 2002, 161(5):1869-1879.

18. Gandy S, et al: Days to criterion as an indicator of toxicity associated with human Alzheimer amyloid-beta oligomers. Ann Neurol 2010, 68(2):220-230.

19. Knobloch $M$, et al: Intracellular Abeta and cognitive deficits precede betaamyloid deposition in transgenic arcAbeta mice. Neurobiol Aging 2007, 28(9):1297-306.

20. Tampellini $D$, et al: Effects of synaptic modulation on beta-amyloid, synaptophysin, and memory performance in Alzheimer's disease transgenic mice. J Neurosci 2010, 30(43):14299-14304.

21. Tampellini D, et al: Impaired beta-Amyloid Secretion in Alzheimer's Disease Pathogenesis. J Neurosci 2011, 31(43):15384-15390. 
22. Nixon RA, Cataldo AM, Mathews PM: The endosomal-lysosomal system of neurons in Alzheimer's disease pathogenesis: a review. Neurochem Res 2000, 25(9-10):1161-1172.

23. Yu WH, et al: Autophagic vacuoles are enriched in amyloid precursor protein-secretase activities: implications for beta-amyloid peptide over-production and localization in Alzheimer's disease. Int J Biochem Cell Biol 2004, 36(12):2531-2540.

24. Adamec $E$, et al: Up-regulation of the lysosomal system in experimental models of neuronal injury: implications for Alzheimer's disease. Neurosci. 2000, 100(3):663-675.

25. Yang AJ, et al: Loss of endosomal/lysosomal membrane impermeability is an early event in amyloid Abeta1-42 pathogenesis. J Neurosci Res 1998, 52(6):691-698.

26. Liu J, et al: Predominant release of lysosomal enzymes by newborn rat microglia after LPS treatment revealed by proteomic studies. J Proteome Res 2008, 7(5):2033-2049.

27. Cataldo AM, et al: Abeta localization in abnormal endosomes: association with earliest Abeta elevations in $A D$ and Down syndrome. Neurobiol Aging 2004, 25(10):1263-1272.

28. Langui $D$, et al: Subcellular topography of neuronal Abeta peptide in APPxPS1 transgenic mice. Am J Pathol 2004, 165(5):1465-1477.

29. Zheng $L$, et al: Autophagy of amyloid beta-protein in differentiated neuroblastoma cells exposed to oxidative stress. Neurosci Lett 2006, 394(3):184-189.

30. Zheng $L$, et al: Oxidative stress induces macroautophagy of amyloid beta-protein and ensuing apoptosis. Free Radic Biol Med 2009, 46(3):422-429.

31. Zheng L, Marcusson J, Terman A: Oxidative stress and Alzheimer disease: the autophagy connection? Autophagy 2006, 2(2):143-145.

32. Zheng $L$, et al: Oxidative stress induces intralysosomal accumulation of Alzheimer amyloid beta-protein in cultured neuroblastoma cells. Ann N Y Acad Sci 2006, 1067:248-251.

33. Eva C, et al: Primary cultures of corticostriatal cells from newborn rats: a model to study muscarinic receptor subtypes regulation and function. J Mol Neurosci 1990, 2(3):143-153.

34. Verderio $C$, et al: Tetanus toxin blocks the exocytosis of synaptic vesicles clustered at synapses but not of synaptic vesicles in isolated axons. J Neurosci 1999, 19(16):6723-6732.

35. Kamal $A$, et al: Kinesin-mediated axonal transport of a membrane compartment containing beta-secretase and presenilin-1 requires APP. Nature 2001, 414(6864):643-648.

36. Yankner BA, et al: Neurotoxicity of a fragment of the amyloid precursor associated with Alzheimer's disease. Science 1989, 245(4916):417-420.

37. Kang J, et al: The precursor of Alzheimer's disease amyloid A4 protein resembles a cell-surface receptor. Nature 1987, 325(6106):733-736.

38. Grigoriev I, et al: Rab6, Rab8, and MICAL3 cooperate in controlling docking and fusion of exocytotic carriers. Curr Biol 2011, 21(11):967-974.

39. Diaz E, Schimmoller F, Pfeffer SR: A novel Rab9 effector required for endosome-to-TGN transport. J Cell Biol 1997, 138(2):283-290.

40. Gouras GK, Almeida CG, Takahashi RH: Intraneuronal Abeta accumulation and origin of plaques in Alzheimer's disease. Neurobiol Aging 2005, 26 (9):1235-1244.

41. Xu H, et al: Generation of Alzheimer beta-amyloid protein in the trans-Golgi network in the apparent absence of vesicle formation. Proc Natl Acad Sci USA 1997, 94(8):3748-3752.

42. Hansson Petersen CA, et al: The amyloid beta-peptide is imported into mitochondria via the TOM import machinery and localized to mitochondrial cristae. Proc Natl Acad Sci USA 2008, 105(35):13145-13150.

43. Pasternak SH, Callahan JW, Mahuran DJ: The role of the endosomal/ lysosomal system in amyloid-beta production and the pathophysiology of Alzheimer's disease: reexamining the spatial paradox from a lysosomal perspective. J Alzheimers Dis 2004, 6(1):53-65.

44. Takahashi RH, et al: Oligomerization of Alzheimer's beta-amyloid within processes and synapses of cultured neurons and brain. J Neurosci 2004 24(14):3592-3599.

45. Billings LM, et al: Intraneuronal Abeta causes the onset of early Alzheimer's disease-related cognitive deficits in transgenic mice. Neuron 2005, 45(5):675-688

46. Buckig A, et al: Cytosolic and nuclear aggregation of the amyloid beta-peptide following its expression in the endoplasmic reticulum. Histochem Cell Biol 2002, 118(5):353-360.
47. Lee EK, et al: Cytosolic amyloid-beta peptide 42 escaping from degradation induces cell death. Biochem Biophys Res Commun 2006, 344(2):471-477.

48. Maxfield FR, Wustner D: Intracellular cholesterol transport. J Clin Invest 2002, 110(7):891-898.

49. Ditaranto $\mathrm{K}$, Tekirian $\mathrm{TL}$, Yang AJ: Lysosomal membrane damage in soluble Abeta-mediated cell death in Alzheimer's disease. Neurobiol Dis 2001, 8(1):19-31.

50. Wang $\mathrm{H}$, et al: Amyloid-beta1-42 induces reactive oxygen speciesmediated autophagic cell death in U87 and SH-SY5Y cells. J Alzheimers Dis 2010, 21(2):597-610.

51. $\mathrm{Ma} \mathrm{G}, \mathrm{Chen} \mathrm{S}$ : Diazoxide and $\mathrm{N}$ omega-nitro-L-arginine counteracted $\mathrm{A}$ beta 1-42-induced cytotoxicity. Neuroreport 2004, 15(11):1813-1817.

52. Tampellini D, Gouras GK: Synapses, synaptic activity and intraneuronal abeta in Alzheimer's disease. Front Aging Neurosci 2010, 2(13). doi:10.3389/fnagi.2010.00013.

53. Cirrito JR, et al: Synaptic activity regulates interstitial fluid amyloid-beta levels in vivo. Neuron 2005, 48(6):913-922.

54. Shengdi Chen JCZ: Translational Neurodegeneration, a platform to share knowledge and experience in translational study of neurodegenerative diseases. Translational Neurodegeneration 2012, 1(1). doi:10.1186/2047-9158-1-1.

doi:10.1186/2047-9158-1-19

Cite this article as: Zheng et al:: Intracellular distribution of amyloid beta peptide and its relationship to the lysosomal system. Translational Neurodegeneration 2012 1:19.

\section{Submit your next manuscript to BioMed Central and take full advantage of:}

- Convenient online submission

- Thorough peer review

- No space constraints or color figure charges

- Immediate publication on acceptance

- Inclusion in PubMed, CAS, Scopus and Google Scholar

- Research which is freely available for redistribution 